at a reasonable cost the best measurement for routıne determination is $\mathrm{MEF}_{25 \mathrm{FVC}}$. If only a spirometer is available, however, the best measurement is MMEF. Bronchial obstruction may be confirmed by the reaction to bronchodilatation. This can be easily determined after inhaling one puff of a $\beta$-sympathomimetic aerosol, which, if inhaled correctly, has a bronchodilating effect equal to that of thiazinamium. ${ }^{22}$ Young people with apparent bronchial obstruction should be considered to be potentially at risk of obstructive lung disease in adult life. They should therefore be prevented from smoking, receive prompt treatment for eventual bronchial obstruction and respiratory infections, and be given adequate vaccination schedules, particularly for influenza.

\section{References}

${ }^{1}$ Cade, J F, and Pain, M C F, Australian and New Zealand Fournal of Medicine, 1973, 3, 545.

2 Levison, H, et al, Pediatric Clinics of North America, 1974, 21, 951.

3 Palmer, K N V, and Kelman, G R, British Medical fournal, 1975, 1, 485.

${ }^{4}$ Higgins, M W, and Keller, J B, American Review of Respiratory Diseases, 1973, 106, 873

5 Sobol, B, Park, S S, and Emirgil, C, American Review of Respiratory Diseases, 1973, 107, 753.
${ }^{6}$ Ingram, R H, and Schilder, D P, fournal of Applied Physiology, 1966, 21, 1821.

${ }^{7}$ Mead, J, et al, fournal of Applied Physiology, 1967, 22, 95.

${ }^{8}$ Zapletal, A, Paul, T, and Samánek, M, Ceskoslovenská Pediatrie, 1976, 31, 532 .

${ }^{9}$ Kerrebijn, K F, Hoogeveen-Schroot, H C A, and van der Wal, M C, Acta Paediatrica Scandinavica, 1977, suppl No 261, p 62, table 12

${ }^{10}$ Leeder, S R, et al, Bulletin Européen de Physiopathologie, 1977, 13, 249.

11 Löwenberg, A, thesis, 1959, p 131.

12 Bouhuys, A, in Airway Dynamics, Physiology and Pharmacology, ed A Bouhuys, p 263. Springfield, Illinois, Charles Thomas, 1970.

13 Orehek, P, and Gayrard, P, Bulletin Européen de Physiopathologie, 1976 $12,565$.

14 Zapletal, A, et al, Pediatrics, 1971, 48, 64.

15 Olive, J T, and Hyatt, R E, American Review of Respiratory Diseases, $1972,106,366$.

${ }^{16}$ Hill, D J, et al, Archives of Disease in Childhood, 1972, 47, 874.

${ }^{17}$ Cooper, D M, et al, American Review of Respiratory Diseases, 1974, 109, 519.

${ }^{18}$ Hill, D J, Landau, L I, and Phelan, P D, American Review of Respiratory Diseases, 1972, 106, 873

19 Burrows, B, Knudson, R J, and Lebowitz, M D, American Review of Respiratory Diseases, 1977, 115, 751 .

20 Blair, H, Archives of Disease in Childhood, 1977, 52, 613.

${ }^{21}$ Colley, J R T, Douglas, J W B, and Reid, D D, British Medical fournal, 1973, 3, 195.

22 Koster, K, and Kerrebijn, K F, unpublished data.

(Accepted 18 fanuary 1978)

\title{
Intellectual impairment in chronic renal failure
}

\author{
A ENGLISH, R D SAVAGE, P G BRITTON, M K WARD, D N S KERR
}

British Medical fournal, 1978, 1, 888-890

\section{Summary}

In a dialysis centre with a high tap water aluminium content and a known high incidence of dialysis encephalopathy, 29 patients undertaking regular home dialysis, without clinical evidence of encephalopathy, were studied with a battery of psychological tests that have proved useful in detecting early organic intellectual deterioration in other conditions. Full-scale intelligence quotient, as measured by the Wechsler Adult Intelligence Scale, did not differ significantly from that of the normal population, but the patients showed significant deficiencies in three tests of performance-namely, digit symbol, block design, and picture arrangement.

The ability to acquire new information in relation to performance was impaired and the abnormality increased with time on dialysis. Such tests should be useful in early detection of dialysis dementia at a reversible stage.

\section{Newcastle Area Health Authority (Teaching)}

A ENGLISH, Msc, clinical psychologist (now at Airedale General Hospital, Steeton, W Yorks)

University Department of Psychological Medicine, Newcastle upon Tyne NE1 4LP

R D SAVAGE, DSC, FBPSs, senior lecturer (now professor of psychology, Murdoch University, Perth, W Australia)

P G BRITTON, PHD, ABPSS, lecturer

University Department of Medicine, Newcastle upon Tyne NE1 4LP $M$ K WARD, MB, MRCP, lecturer

D N S KERR, MSC, FRCP, professor

\section{Introduction}

Home haemodialysis requires skill, concentration, alertness, and conscientiousness. We rate it in the same class as learning to drive and maintain a car. Not all patients in renal failure can acquire the necessary skills, and about a third of the highly selected group who are accepted for treatment in the UK are never asked to do so. It is crucially important that those who do undertake their own treatment should maintain their intellectual capacity. They face the universal hazard of aging plus several neurological complications of renal failure, ${ }^{1}$ of which the most important is dialysis encephalopathy. ${ }^{2-12}$ This syndrome is usually recognised when the patient develops speech disturbance, apraxia, myoclonus, or fits. By that time home dialysis is already hazardous and the patient doomed to progressive and usually fatal disease. Few patients who reach this stage survive; improvement after transplantation has been recorded in an isolated case, ${ }^{13}$ and two of our patients stopped deteriorating after successful grafts, but in most cases the disease progresses to its lethal conclusion despite good renal function.

In several of our 17 patients with this disease, personality change and intellectual impairment preceded overt features of the illness but were recognised only retrospectively. ${ }^{7}$ Investigation of one early case showed that the intellectual deficit had been seriously underestimated by the clinicians in charge. We therefore undertook a formal study of intellectual functioning in a group of patients who were at serious risk of developing dialysis encephalopathy but had no evident features of the syndrome to see whether early dementia was present.

\section{Patients and methods}

Twenty-nine patients ( 15 men and 14 women) attending the followup clinic for home haemodialysis were referred for intellectual assessment. The first few were chosen because of suspected difficulties with 
dialysis but most were a random sample of patients undergoing the procedure throughout northern England, one of the five regions of the UK with a high incidence of dialysis encephalopathy. The nature of the investigation was explained and their voluntary co-operation obtained. The patients were aged 17-58 years (mean 40.1 years) and had undergone haemodialysis for an average of 35.5 months (range 8-78 months). During the investigation five of them died, four from dialysis encephalopathy; one of these showed some intellectual improvement after transplantation but the syndrome eventually progressed to death. The distribution of renal diagnoses was not appreciably different from that in the whole dialysis population.

Intellect was studied according to the scheme of Savage et al, ${ }^{14}$ which was devised to investigate the structure of intellect in the aged and impairment with age but which has been successfully applied to children with neurological deficits. ${ }^{15}$ The model separates intellectual functioning into intellectual level and learning ability, which can be further subdivided into their verbal and performance aspects. Since some intellectual functions are affected by dialysis ${ }^{16}$ all tests were conducted 12-48 hours (mean 28 hours) after the last treatment.

Psychological procedures used were the full Weschler Adult Intelligence Scale (WAIS), ${ }^{17}$ the Walton-Black Modified Word Learning Test (MWLT), ${ }^{18}$ and the Block Design Learning Test (BDLT). ${ }^{19}$ Three patients did not complete all the subtests in the WAIS, so their intelligence quotient (IQ) scores were calculated from the available data. For the MWLT 10 words whose meanings were unknown to the subject were required. The first 10 consecutive failures on the WAIS vocabulary scale were used for this purpose. When 10 consecutive failures were not obtained the Mill Hill Vocabulary Scale was used. The 10 words and their meanings were shown to the patient, and then on presentation of the stimulus word (in random order) the patient was asked to recall the meaning. This sequence was repeated until the patient got six words out of 10 correct at one trial. Different expressions were used to define each test word in successive trials, so this was not merely a test of rote learning. Testing was stopped after six trials. High scores represented poor learning, the maximum score being 30 .

The BDLT uses the first of three successive failures on the WAIS. The patient is asked to try again to make the first failed design and to examine his solutions carefully. This is repeated five more times. On each occasion the time taken is recorded and the percentage improvement on initial performance calculated. As some patients are unable to succeed no matter how much time they are given, the correct solution is demonstrated after five minutes and the test repeated. If they fail again a zero score is assigned.

\section{Results}

The table shows the levels of intellectual functioning and learning abilities of the 29 patients compared with those of a normal population. The overall intellectual level, as measured by the WAIS full-scale IQ, did not differ significantly from normal. The patients' performance IQ was lower than normal, however, although not significantly so. This was due mainly to the digit symbol, block design, and picture

Levels of Intellectual functioning in dialysis patients compared with normal population

\begin{tabular}{|c|c|c|c|c|c|}
\hline & & & & No tested & Mean \pm SD \\
\hline \multicolumn{6}{|c|}{ Main variables (mean result for normal population $100 \cdot 0 \pm 15 \cdot 0$ ) } \\
\hline $\begin{array}{l}\text { Verbal IQ } \\
\text { Performance IQ } \\
\text { Full-scale IQ } \ldots\end{array}$ & $\begin{array}{l}. . \\
\cdots\end{array}$ & $\begin{array}{l}. . \\
\cdots\end{array}$ & $\begin{array}{l}\cdots \\
\cdots\end{array}$ & $\begin{array}{l}29 \\
29 \\
29\end{array}$ & $\begin{array}{r}102 \cdot 1 \pm 18 \cdot 1 \\
96 \cdot 9 \pm 15 \cdot 2 \\
99 \cdot 9 \pm 17 \cdot 0\end{array}$ \\
\hline \multicolumn{6}{|c|}{$W A I S$ subtests (mean result for normal population $10 \cdot 0 \pm 3 \cdot 0$ ) } \\
\hline 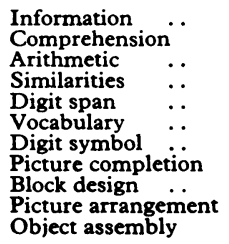 & $\begin{array}{l}. \\
\because \\
\because \\
\because \\
\because \\
\because \\
\because \\
\cdots\end{array}$ & $\begin{array}{l}\ldots \\
\because \\
\cdots \\
\cdots \\
\cdots \\
\cdots \\
\cdots \\
\cdots\end{array}$ & $\begin{array}{l}\cdots \\
\cdots \\
\cdots \\
\cdots \\
\cdots \\
\cdots \\
\cdots\end{array}$ & $\begin{array}{l}29 \\
29 \\
29 \\
29 \\
29 \\
28 \\
28 \\
29 \\
28 \\
27 \\
27\end{array}$ & $\begin{array}{r}9 \cdot 8 \pm 2 \cdot 9 \\
11 \cdot 4 \pm 4 \cdot 2 \\
9 \cdot 3 \pm 3 \cdot 7 \\
9 \cdot 9 \pm 3 \cdot 1 \\
9 \cdot 3 \pm 2 \cdot 8 \\
11 \cdot 3 \pm 3 \cdot 4 \\
6 \cdot 8^{*} \pm 2 \cdot 0 \\
9 \cdot 6 \pm 2 \cdot 0 \\
8 \cdot 5^{*} \pm 2 \cdot 9 \\
8 \cdot 1 * \pm 2 \cdot 0 \\
9 \cdot 2 \pm 3 \cdot 1\end{array}$ \\
\hline \multicolumn{6}{|c|}{ Impairment of level and learning tests } \\
\hline $\begin{array}{l}\text { Deterioration quotien } \\
\text { MWLT .. } \\
\text { BDLT .. }\end{array}$ & a & $\ddot{n}$ & $\ddot{x}$ & $\begin{array}{l}27 \\
27 \\
26\end{array}$ & $\begin{array}{r}7.9 \pm 14.5 \\
15.0 \pm 13.9 \\
48.9 \pm 21.8\end{array}$ \\
\hline
\end{tabular}

*P $<0.05$ compared with result for normal population. arrangement subtests, all of which produced scores significantly below normal. The impairment of intellectual level as represented by the Wechsler deterioration quotient was also outside the normal range. The data on verbal learning obtained with the MWLT and performance learning obtained with the BDLT were consistent with the findings of Walton and Black ${ }^{20}$ and Savage and $\mathrm{Hall}^{19}$ respectively and did not indicate any gross learning abnormality in the sample as a whole.

Cognitive data were compared with other information such as age, sex, length of dialysis, and biochemical variables by a multipleregression technique. The analysis suggested that of the cognitive data those obtained with the BDLT bore the strongest relation to duration of dialysis. Other major cognitive variables did not add significantly to the predictive value of the multiple-regression equation. Thus as duration of dialysis increases performance learning ability, as measured by the BDLT, decreases. Discriminant function analysis between the length of time on dialysis for the eight longest and eight shortest times confirmed the importance of this variable.

\section{Discussion}

Savage $e t \mathrm{al}^{14}$ suggested that patients who are deteriorating intellectually may have difficulty in learning new tasks long before there is any evident deterioration in intellectual level. This has some relevance to home haemodialysis: techniques change from year to year; equipment is updated; new monitors are added; hours of dialysis are contracted and additional precautions introduced to compensate. Ability to acquire new information and skills is therefore important to these patients.

We found that patients at high risk of developing dialysis encephalopathy have detectable abnormalities in intellectual function before they show overt features of the disease. Further, longitudinal studies will show how closely these tests predict which patients will progress. The problem has been given new urgency by recent insights into dialysis encephalopathy. There is now little doubt that it is caused by accumulation of aluminium ${ }^{6-9}$ and that the water used in the dialysis fluid is the main source. In areas of high incidence, such as northern England, purification of tap water by deionisation or reverse osmosis is now mandatory, and the epidemics that have scourged the Newcastle, Sheffield, Leeds, Glasgow, and Southwestern regions should not recur. It is already apparent, however, that most dialysis patients are accumulating aluminium and that once inside it is difficult to remove. ${ }^{21}$ An early-warning system is needed to detect impending disaster, particularly in the many patients now receiving dialysis who already have a high body aluminium load. Early transplantation or (very expensive) ultrapurification of water may be needed to halt progression of dialysis encephalopathy. Results of serial tests of learning ability such as the BDLT should be compared with biochemical measurements-for example, bone aluminium-in the search for a suitable early warning.

\section{References}

1 Teschan, P E, and Ginn, H E, in Clinical Aspects of Uraemia and Dialysis, ed S G Massry and A L Sellers. Springfield, Illinois, Thomas, 1976.

2 Alfrey, A C, et al, Transactions of the American Society for Artificial Internal Organs, 1972, 18, 257.

3 Mahurkar, S D, et al, Lancet, 1973, 1, 1412.

4 Chokroverty, S, et al, fournal of Neurology; Neurosurgery and Psychiatry, 1976, 39, 411.

${ }^{5}$ Barratt, L J, and Lawrence, J R, Australian and New Zealand Fournal of Medicine, 1975, 5, 62.

' Alfrey, A C, LeGendre, G R, and Kaehny, W D, New England fournal of Medicine, 1976, 294, 184.

${ }^{7}$ Ward, M K, et al, Proceedings of the European Dialysis and Transplant Association, 1976, 13, 348.

${ }^{8}$ Flendrig, J A, Kruis, H, and Das, H A, Proceedings of the European Dialysis and Transplant Association, 1976, 13, 355.

- Platts, M M, Goode, G C, and Hislop, J S, British Medical fournal, 1977, 2, 657.

10 Burks, J S, et al, Lancet, 1976, 1, 764.

11 Lancet, 1976, 1, 349.

12 British Medical fournal, 1976, 2, 1213. 
13 Sullivan, P A, Murnaghan, D J, and Callaghan, N, British Medical fournal, $1977,2,740$.

14 Savage, R D, et al, Intellectual Functioning in the Aged. London, Methuen, 1973 .

15 Adams, M, MSc thesis "Intellectual level and learning in children with cerebral palsy and Duchenne muscular dystrophy," University of Newcastle upon Tyne, 1974.

16 Teschan, P E, et al, Transactions of the American Society for Artificial Internal Organs, 1974, 20A, 388.
17 Weschler, D, Manual for Weschler Adult Intelligence Scale. New York, Psychological Corporation, 1955.

18 Walton, D, and Black, D A, Fournal of Mental Science, 1959, 105, 807

19 Savage, R D, and Hall, E H, British Fournal of Psychiatry, 1973, 122, 721.

20 Walton, D, and Black, D A, British Fournal of Medical Psychology, 1957, 30, 270.

${ }^{21}$ Kaehny, W D, et al, Kidney International, 1977, 12, 361.

(Accepted 18 fanuary 1978)

\section{SHORT REPORTS}

\section{Severe Dettol (chloroxylenol and terpineol) poisoning}

Phenol poisoning is recognised as being serious, but chloroxylenol, a common constituent of proprietary disinfectants is regarded to be of low $^{12}$ to moderate ${ }^{3}$ toxicity, and the Dettol label describes it as non-poisonous. Although reference is made to a personal communication about a patient who died of an air embolus after attempting to induce an abortion by instilling a chloroxylenol disinfectant into her uterus, we failed to find any reports of serious poisoning after oral ingestion of chloroxylenol. We report here such a case.

\section{Case report}

A 70-year-old depressed woman was admitted to the casualty department 30 minutes after attempting to commit suicide by ingesting $350 \mathrm{ml}$ of household Dettol (Reckit and Colman), which contains chloroxylenol $48 \mathrm{~g} / 1$, terpineol, and ethyl alcohol $( \pm 7 \cdot 0 \%)$.

She was in a deep coma, areflexic, and unresponsive to painful stimuli, and her pupils were moderately constricted showing little response to light. Her systolic blood pressure was $30 \mathrm{~mm} \mathrm{Hg}$, and her pulse 60 beats $/ \mathrm{min}$; she was breathing spontaneously at 8 per minute. Her rectal temperature was $35^{\circ} \mathrm{C}$ and she had signs of peripheral venous dilatation and a raised jugular venous pressure. There were no signs of corrosion or chemical irritation of the skin or mucosae and her ECG showed pronounced ischaemic changes.

An intravenous line was established, oxygen given via a face mask, and the stomach content carefully aspirated via a Ryles tube inserted through a nostril. The stomach content was milky and smelt strongly of Dettol. Careful gastric lavage was performed with small amounts of water, and afterwards $100 \mathrm{ml}$ of liquid paraffin was left in the stomach. The patient was then transferred to the intensive care unit, where her vital functions were monitored continuously. Her blood pressure was controlled by dopamine infusion. About four hours after admission she developed a nodal tachycardia, which responded well to intravenous verapamil. After six to eight hours she started to regain consciousness and was fully conscious after 24 hours (see figure). She was then transferred to the general psychiatric ward and apart from severe watery diarrhoea during the first 48 hours recovered uneventfully.

Thin-layer chromatography of the gastric aspirate was compared with that

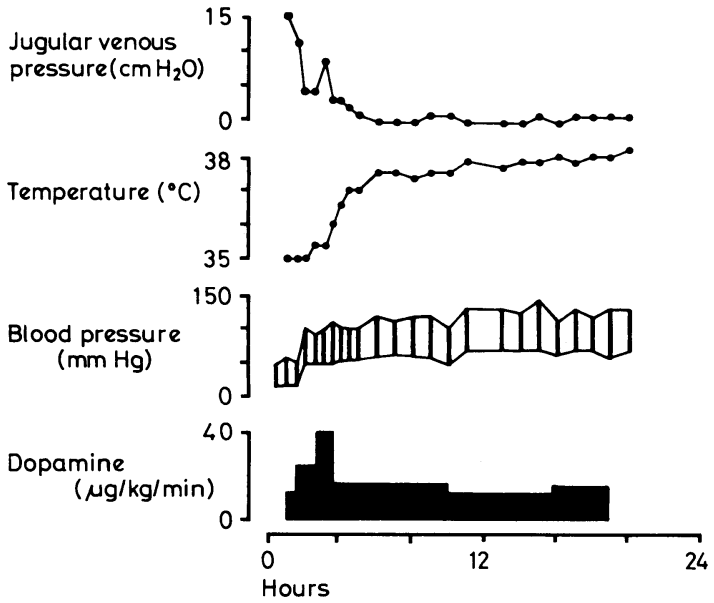

Clinical course of patient during the first 24 hours. of Dettol and its constituents and the presence of chloroxylenol and terpineol confirmed. Minute amounts of free chloroxylenol were present in the urine, but no chloroxylenol could be detected in the blood, although several phenolic compounds presumed to be metabolites and conjugation products were present. Large amounts of conjugated chloroxylenol were present in the urine.

Blood obtained on admission also showed an ethyl alcohol concentration of $700 \mathrm{mg} / 1$ and a sample of Dettol a concentration of $7 \cdot 3 \%$. Extensive gaschromatography and thin-layer chromatography failed to show the presence of other potentially toxic substances.

\section{Comment}

This case has some interesting features. Apart from the rarity of the ingestion of such a large amount of this disinfectant (equivalent to $16.8 \mathrm{~g}$ of chloroxylenol), the rapidity of the development of profound central nervous system and cardiovascular depression and the remarkably rapid recovery are striking. The body seems to have very efficient mechanisms for rapidly detoxifying and eliminating chloroxylenol.

We thank the medical superintendent of the National Hospital, Bloemfontein, for permission to report this case.

1 Blacow, N W (editor), Martindale: The Extra Pharmacopoea, p 183, 26th edn. London, Pharmaceutical Press, 1972.

2 Clarke, E G C (editor), Isolation of Drugs, vol 1, p 254. London, Pharmaceutical Press, 1974.

${ }^{3}$ Gosselin, R E, et al, Clinical Toxicology of Commercial Products, 4th edn, p 131. Baltimore, Williams and Wilkins, 1976

(Accepted 23 November 1977)

Department of Pharmacology, University of the OFS and Academi Hospitals, Bloemfontein, Republic of South Africa

PIETER JOUBERT, MMEDSC, FCPSA, senior lecturer (present address: Medical University of Southern Africa, PO box 4302, Pretoria)

HANS HUNDT, BSC, chief professional officer

Department of Critical Care, University of the OFS and Academic Hospitals, Bloemfontein, Republic of South Africa PIETER DU TOIT, MMED, FFASA, head

\section{Assessment of hypoproteinaemic oedema: a simple physical sign}

It is well known that hypoproteinaemia can cause pitting oedema. We have found that hypoproteinaemic oedema pits and recovers differently from other types of oedema but can find no reference to this in reports or texts on physical signs. We therefore investigated the relation between the rate of recovery of pitting and the serum albumin concentration in a group of oedematous patients.

\section{Patients, methods, and results}

Over four months all patients coming to our notice who had had pitting eg oedema for less than three months were studied. Their oedema was 